\title{
LA ORACIÓN SUBORDINADA SUSTANTIVA EN EL TEXTO ESCRITO EN ESPAÑOL
}

\author{
José M. Bustos GisBerT \\ Universidad de Salamanca
}

Resumen

Este trabajo se fija en el rendimiento de la subordinación sustantiva en el texto escrito en español. Se evalúa como se emplea en cuatro modos del discurso (narraciones, descripciones, instrucciones y exposiciones) y se estudia el rendimiento de tales subordinadas según asuman función de sujeto, de complemento directo o de complemento preposicional, sea este del verbo, del nombre o del adjetivo. Se presta especial atención a la morfología de los verbos subordinados y a las condiciones que llevan a que tales subordinadas se construyan en indicativo, en subjuntivo o en infinitivo. Asimismo, se valora su uso en construcciones indirectas y de estilo directo.

Palabras clave: Subordinación sustantiva, sintaxis del discurso escrito, tipos textuales, modo verbal.

\section{SUBSTANTIVE SUBORDINATION IN SPANISH WRITTEN TEXTS}

\section{Abstract}

This paper focuses on the performance of substantive subordination in Spanish written texts. The article evaluates how it is used in four modes of discourse (narrations, descriptions, instructions and expositions). It also studies the use of such subordinates when they function as the subject, the direct complement or the prepositional complement (of a verb, a noun or an adjective) within the main clause. Special attention is paid to the morphology of subordinate verbs and to the conditions that lead such subordinates to be constructed in indicative, subjunctive or infinitive. Moreover, its patterns of usage are specifically analysed in indirect and direct speech structures.

Keywords: Substantive subordination, syntax of written speech, textual typology, verbal mood. 


\section{INTRODUCCIÓN}

El trabajo que presentamos a continuación se incluye en un amplio proyecto de análisis de la naturaleza sintáctica del discurso escrito en español que persigue llevar a cabo una evaluación cuantitativa y cualitativa referida a cómo emplean usuarios competentes las diferentes opciones sintácticas que ofrece nuestra lengua en la construcción del discurso escrito (véanse Bustos Gisbert, 2017 y 2018). Es, pues, un estudio de actuación lingüística.

El rendimiento general de las distintas construcciones subordinadas y las diferencias observadas con frecuencia tienen que ver con la naturaleza tipológica de los textos evaluados. Lo hemos estudiado de manera global en Bustos Gisbert (2018), donde se ha propuesto una clasificación de las mismas que quiere ser coherente desde un punto de vista categorial. Es necesario seguir perfilando nuestra investigación y queremos hacerlo evaluando el uso que exhibe la construcción más usada, como es el caso de la subordinación sustantiva.

El trabajo se asienta en el estudio de un corpus de textos escritos; tal elección se basa en la convicción de que es en esos contextos donde se hace un uso formalmente más complejo del sistema lingüístico ${ }^{1}$. De un lado, por la naturaleza diferida de la comunicación escrita, que exige un mayor grado precisión formal al enunciador en tanto que no comparte unas coordenadas espaciotemporales con su destinatario, razón por la cual este no podrá solicitar aclaraciones, reformulaciones, ni tampoco confirmar sus interpretaciones; por tal motivo, el emisor se ve obligado, en un entorno de comunicación cooperativa como en el que nos queremos ubicar, a buscar los mecanismos lingüísticos que faciliten la tarea comprensiva. De otro, por su naturaleza monológica y no dependiente: el emisor es el único responsable de la construcción formal del texto y usa con plena libertad los recursos de la lengua para adecuarlos al mensaje que desea transmitir y con la intención que a este subyazca. La po-

${ }^{1}$ Di Tullio (2002: 57): «La característica discursiva que se suele destacar, al oponer el texto escrito al hablado, es el predominio de la hipotaxis sobre la parataxis. El discurso hipotáctico, que consiste en la unión subordinativa de oraciones, establece una jerarquía entre las unidades relacionadas. El discurso paratáctico, en cambio, discurre en un único plano, en el que se van ordenando sucesivas unidades». 
sibilidad de reflexionar y de reformular el discurso antes de que este llegue al destinatario le permite dotarle de un nivel de complejidad a priori mayor que en el caso de la comunicación prototípicamente conversacional, que es fundamentalmente interactiva y dependiente.

La investigación quiere ser fiable desde una perspectiva tipológica y discursiva. Por ello parte del análisis del mismo corpus ya usado para investigaciones precedentes. Se trata de 369 textos de entre 400 y 450 palabras tomados de Corputrad, que reflejan de manera razonablemente equilibrada cuatro modos del discurso: narración, descripción, exposición e instrucción. Los escritos no son estrictamente representativos de ningún género en tanto que son simulaciones didácticas ${ }^{2}$. Sin embargo, son tipológicamente consistentes en la medida en que han sido redactados por usuarios competentes que han volcado en ellos los conocimientos adquiridos en lo relativo a la construcción de textos. Estos son los datos relativos al corpus empleado:

\begin{tabular}{l|cccccc}
\multicolumn{1}{c}{} & Textos & Palabras & $\begin{array}{l}\text { Enun- } \\
\text { ciados }\end{array}$ & $\begin{array}{l}\text { Predica- } \\
\text { ciones }\end{array}$ & $\begin{array}{l}\text { Predica- } \\
\text { ciones } \\
\text { subordi- } \\
\text { nadas }\end{array}$ & $\begin{array}{l}\text { Oraciones } \\
\text { subordina- } \\
\text { das }\end{array}$ \\
\hline Narrativo & 73 & 25.654 & 1.267 & 3.199 & 1.741 & 1.669 \\
Descriptivo & 102 & 43.270 & 2.807 & 6.220 & 2.812 & 2.683 \\
Instructivo & 88 & 38.926 & 2.855 & 6.837 & 3.695 & 3.495 \\
Expositivo & 106 & 44.672 & 2.482 & 6.550 & 3.834 & 3.627 \\
TOTAL & 369 & 152.522 & 9.411 & 22.806 & 12.082 & 11.474 \\
& & & & & &
\end{tabular}

Tabla 1. Corpus de trabajo ${ }^{3}$

${ }^{2}$ Corputrad es un corpus de textos escritos originalmente en español por estudiantes de primer curso del Grado en Traducción e Interpretación de la Universidad de Salamanca. En la actualidad reúne más de 4.500 textos redactados entre 2006 y 2015 por 600 informantes distintos y acumula aproximadamente tres millones de palabras.

${ }^{3}$ Los géneros textuales presentes en este estudio son los siguientes: noticia periodística, retrato, descripción de una vivienda, manual de instrucciones y artículo de opinión. 


\section{CONSIDERACIONES GENERALES}

Las subordinadas sustantivas con función argumental suman casi el $38 \%$ de todas las identificadas en el corpus y se mueven en una franja de rendimiento que va desde el $22,55 \%$ en contextos descriptivos hasta casi el $45 \%$ en los instructivos ${ }^{4}$ :

\begin{tabular}{l|lllll}
\multicolumn{2}{c}{ Narrativo } & Descriptivo & Instructivo & Expositivo & Promedio \\
\hline Sustantivas & $34,58 \%$ & $22,55 \%$ & $44,93 \%$ & $43,69 \%$ & $37,83 \%$
\end{tabular}

Tabla 2. Rendimiento de la subordinación sustantiva

Es el tipo de subordinación más utilizado en todos los modos del discurso excepto en la descripción, único caso en el que es superado por las oraciones de relativo, que alcanzan un 33,11\%. El motivo por el cual es la opción más frecuente es fácil de descubrir: se usa para construir complementos argumentales, que son los que el predicado necesita para desarrollar su significado.

Hemos considerado subordinadas sustantivas solo a aquellas utilizadas para la construcción de argumentos oracionales. Para ello nos apoyamos en la definición aportada por la Nueva Gramática de la Lengua Española (NGLE, §1.13o): «las subordinadas sustantivas se denominan también argumentales porque con escasas excepciones [...] son las únicas que constituyen argumentos de algún predicado». La Academia incluye en su descripción las sustantivas de sujeto, de complemento directo y como término de preposición; en este caso podrán cumplir función de complemento del nombre, del adjetivo o del verbo. Asumiendo que en todos los casos se trata efectivamente de subordinadas sustantivas, no incluiremos en el estudio de las subordinadas insertas argumentales aquellas sustantivas que formen complementos preposicionales del verbo que no sean complementos de régimen. Apoyamos nuestra postura en la propia percepción de la $N G L E(\$ 36.1 \mathrm{a})$, que asigna a esos grupos preposicionales función no argumental, sino de adjunto. No obstante, habría que precisar que sería más oportuno hablar de subordinadas fundamentalmente argumentales. De hecho, la NGLE reconoce que podría haber

\footnotetext{
${ }^{4}$ Todos los porcentajes lo son respecto del número de predicaciones verbales subordinadas.
} 
algunas excepciones a la consideración de todas las subordinadas sustantivas como argumentales. Efectivamente, según el texto académico, así sucedería en el caso de algunas de las regidas por sustantivos, concretamente las dependientes de nombres como hecho o idea. Así, al referirse a las subordinadas sustantivas introducidas por la proposición de, afirma que «se ha debatido con intensidad en los últimos años la oposición que se da entre la llamada INTERPRETACIÓN ATRIBUTIVA O APOSITIVA y la llamada INTERPRETACIÓN ARGUMENTAL de los complementos oracionales que introduce esta preposición» (43.5i). En beneficio de la primera está la consideración de que «el elemento que parece complemento resulta ser el verdaderamente central desde el punto de vista semántico» (43.5j): el segmento discontinuo artículo $+\ldots+$ subordinada sustantiva aporta en conjunto cierta información determinativa. En todo caso, la NGLE termina reconociendo que «la distinción a las que se refieren los apartados precedentes es polémica porque el comportamiento sintáctico de los sustantivos de uno y otro grupo no marca con claridad los límites entre ellos» (43.5n) $)^{5}$. Así y todo, y asumiendo la especial naturaleza de tales construcciones, incluiremos dentro de las subordinadas sustantivas como término de preposición todas las que cumplan función de complemento del nombre, sea este argumental o apositivo.

Asimismo, hemos incluido en este estudio las subordinadas sustantivas que subyacen a las construcciones interrogativas y exclamativas indirectas (que en adelante llamaremos construcciones indirectas), y a las construcciones de estilo directo. El rendimiento de unas y otras es muy limitado en nuestro corpus:

${ }^{5}$ En palabras de Leonetti Jungl (1999: 2090): «existen dos tipos básicos de subordinadas sustantivas dependientes de nombres, que podemos denominar 'argumentales' y 'apositivas'. Las primeras funcionan como argumentos seleccionados y regidos por los nombres, mientras que las segundas se comportan como simples modificadores. Solo las sustantivas argumentales, por tanto, son equiparables a las que dependen de verbos y adjetivos (que son siempre argumentos de estos últimos)». 


\begin{tabular}{l|ccccc}
\multicolumn{2}{c}{ Narrativo } & Descriptivo & Instructivo & Expositivo & $\begin{array}{c}\text { Prome- } \\
\text { dio }\end{array}$ \\
\hline $\begin{array}{l}\text { Subordinadas } \\
\text { sustantivas } \\
\text { declarativas }\end{array}$ & $85,71 \%$ & $93,38 \%$ & $95,42 \%$ & $93,01 \%$ & $92,98 \%$ \\
$\begin{array}{l}\text { Construcciones } \\
\text { indirectas }\end{array}$ & $4,15 \%$ & $6,47 \%$ & $4,46 \%$ & $6,63 \%$ & $5,49 \%$ \\
$\begin{array}{l}\text { Construcciones } \\
\text { de estilo }\end{array}$ & $10,13 \%$ & $0,16 \%$ & $0,12 \%$ & $0,36 \%$ & $1,53 \%$ \\
$\begin{array}{l}\text { directo } \\
\text { directo }\end{array}$ & & & & &
\end{tabular}

Tabla 3. Subordinación sustantiva y modalidades enunciativas

\section{FUNCIÓN SINTÁCTICA DE LAS SUBORDINADAS SUSTANTIVAS}

El corpus analizado acumula 4.556 predicaciones subordinadas sustantivas que hemos clasificado en tres funciones argumentales: sujeto, complemento directo y complemento de régimen preposicional. Las correspondientes a este último grupo aparecen desglosadas en las tres opciones reconocidas en la $N G L E$ según esté vinculado a un verbo (CRV), a un nombre (CRN) o a un adjetivo (CRA). Estos son los datos de partida:

\begin{tabular}{c|ccccc} 
Total & Sujeto & C. Directo & CR Verbo & CR Nombre & CR Adjetivo \\
\hline $100 \%$ & $32,18 \%$ & $41,86 \%$ & $13,63 \%$ & $11,06 \%$ & $1,27 \%$
\end{tabular}

Tabla 4. Funciones sintácticas

Las de complemento directo y sujeto acumulan casi tres de cada cuatro casos. El 25\% restante corresponde a los complementos de régimen preposicional, si bien el reparto entre las tres opciones no es en absoluto uniforme: se distribuye de manera equilibrada entre el CRV y el CRN, mientras que el CRA tiene una presencia testimonial en nuestro corpus.

Por otro lado, se detecta alguna variación según la naturaleza enunciativa de las construcciones subordinadas. Si obviamos las de estilo directo, pues todas las identificadas cumplen función de complemento directo, interesa fijarse en las diferencias derivadas de que se trate de construcciones declarativas o indirectas. 


\begin{tabular}{l|lllll}
\multicolumn{1}{c}{ Sujeto } & C. Directo & CR Verbo & CR Nombre & CR Adjetivo \\
\hline Declarativas & $34,31 \%$ & $39,40 \%$ & $13,75 \%$ & $11,18 \%$ & $1,37 \%$ \\
Indirectas & $4,49 \%$ & $67,76 \%$ & $15,51 \%$ & $12,24 \%$ & $0,00 \%$ \\
Promedio & $32,18 \%$ & $41,86 \%$ & $13,63 \%$ & $11,06 \%$ & $1,27 \%$
\end{tabular}

Tabla 5. Funciones sintácticas y modalidad enunciativa

Las declarativas reflejan con bastante fidelidad el empleo general, lo cual no nos sorprende porque representan el 93\% de todas las subordinadas sustantivas. Ahora, bien, en las indirectas se produce un cambio cualitativamente importante, como es el hecho de que su uso en función de sujeto se reduce en un $30 \%$, porcentaje que además se transfiere casi de manera completa a la función de complemento directo.

En segundo lugar, si desagregamos los resultados en virtud de la naturaleza tipológica de los entornos discursivos, observamos algunas diferencias también llamativas:

\begin{tabular}{l|lllll}
\multicolumn{1}{c}{ Sujeto } & C. Directo & CR Verbo & CR Nombre & CR Adjetivo \\
\hline Narrativo & $15,78 \%$ & $64,45 \%$ & $12,79 \%$ & $6,31 \%$ & $0,66 \%$ \\
Descriptivo & $30,70 \%$ & $45,25 \%$ & $12,82 \%$ & $9,65 \%$ & $1,42 \%$ \\
Instructivo & $40,74 \%$ & $36,21 \%$ & $12,73 \%$ & $9,35 \%$ & $0,97 \%$ \\
Expositivo & $30,13 \%$ & $38,00 \%$ & $15,13 \%$ & $15,01 \%$ & $1,74 \%$ \\
Promedio & $32,18 \%$ & $41,86 \%$ & $13,63 \%$ & $11,06 \%$ & $1,27 \%$
\end{tabular}

Tabla 6. Funciones sintácticas y modos del discurso

Los contextos narrativos y, en menor medida, los descriptivos tienden a que la subordinada cumpla una función de complemento directo. Sin embargo, en las secuencias de naturaleza instructiva cabe destacar que la función de sujeto supera a la de complemento directo: es el único contexto en que tal hecho se produce. Este incremento en las construcciones con función de sujeto parece que se asocia a una despersonalización estilística: con el objeto de reducir el carácter impositivo o coercitivo de las instrucciones aportadas no se fija un sujeto preciso que deba cumplirlas. Por su parte, en los entornos expositivos las funciones de complemento de régimen son las más elevadas para las tres opciones estudiadas, y siempre por encima de las medias totales. Tal hecho tiene como resultado 
que su relevancia compuesta suba al $31,8 \%$, porcentaje cercano al correspondiente a las funciones den sujeto y complemento directo. Este aumento puede tener que ver con una tendencia a la nominalización del estilo, resultado de lo cual el uso de las construcciones de CRN aumenta considerablemente respecto del resto de entornos discursivos.

\subsection{En función de sujeto}

Las diferencias de uso de la subordinación sustantiva en función de sujeto según el modo del discurso que refleja la tabla seis se entienden mejor si nos fijamos en los modelos sintácticos en lo que esta se plasma: en casi tres de cada cuatro casos la construcción es atributiva $(74,8 \%)$, en el $16,6 \%$ se trata de construcciones predicativas y en apenas un $8,5 \%$ la identificamos en construcciones de pasiva refleja. La distribución de uso según la naturaleza de los textos es la siguiente:

\begin{tabular}{l|lll} 
EN FUNCIÓN DE SUJETO & Atributivas & Pasivas reflejas & Predicativas \\
\hline Narrativo & $47,37 \%$ & $48,42 \%$ & $4,21 \%$ \\
Descriptivo & $56,99 \%$ & $2,59 \%$ & $40,41 \%$ \\
Instructivo & $81,90 \%$ & $6,08 \%$ & $12,02 \%$ \\
Expositivo & $77,71 \%$ & $6,43 \%$ & $15,86 \%$ \\
Promedio & $74,88 \%$ & $8,49 \%$ & $16,56 \%$
\end{tabular}

Tabla 7. Función de sujeto: naturaleza sintáctica de la subordinada

Como vemos, el uso más repetido es el atributivo. Sin embargo, cuando valoramos los resultados atendiendo a la naturaleza tipológica de los textos, observamos que tal tendencia se refuerza en el caso de los contextos instructivos y expositivos. En cambio, en los narrativos son más frecuentes las subordinadas sustantivas de sujeto en construcciones pasivas, distintivas de este modo del discurso: en él reúnen el $48 \%$ de los casos, mientras que en los restantes oscila entre el $2,5 \%$ y el $8,5 \%$. Finalmente, observamos que las predicativas son propias de las secuencias descriptivas.

La predisposición a incorporar subordinadas sustantivas con función de sujeto en una construcción atributiva parece que tiene que ver con el rendimiento que adquieren determinadas expresiones de modalización 
deóntica. Fijémonos en los textos instructivos, que son los que más utilizan esta opción; en el 77\% se detecta esa función argumentativa que, por otra parte, es muy habitual en tal modo del discurso ${ }^{6}$ :

(1) Una muy buena idea es escuchar ritmos clásicos, pues se ha demostrado que las melodías lentas y suaves tranquilizan a los bebés. $(I N-14)^{7}$

En cambio, si nos detenemos en las mismas construcciones atributivas, pero en entornos narrativos, el $43 \%$ de los casos consignados son enunciados no modalizados. El 41\% recoge modalizaciones valorativas; solo el 2\%, deónticas; y el 13\%, epistémicas:

(2) Si se confirma su culpabilidad, es muy posible que gran parte de su producción se retire del mercado. (NA-5)

Por tanto, la vinculación entre la construcción subordinada con función de sujeto y las modalizaciones deónticas podría explicar que en la narración el porcentaje de frecuencia se reduzca un 30\% en tanto que en ella tales modalizaciones bajan de rendimiento.

En las atributivas, casi el 56\% de los verbos subordinados están en forma no personal, el $17 \%$ en indicativo y el $27 \%$ en subjuntivo:

\begin{tabular}{l|lll}
\multicolumn{1}{l|}{ ATRIBUTIVAS } & Indicativo & Subjuntivo & No personal \\
\hline Narrativo & $26,67 \%$ & $37,78 \%$ & $35,56 \%$ \\
Descriptivo & $58,18 \%$ & $5,45 \%$ & $36,36 \%$ \\
Instructivo & $2,72 \%$ & $34,24 \%$ & $63,04 \%$ \\
Expositivo & $25,58 \%$ & $21,45 \%$ & $52,97 \%$ \\
Promedio & $17,37 \%$ & $26,97 \%$ & $55,67 \%$
\end{tabular}

Tabla 8. Función de sujeto: atributivas

Las construcciones de infinitivo se prefieren muy especialmente en los contextos instructivos; parece que ello se justifica por una tendencia

\footnotetext{
${ }^{6}$ Las modalizaciones valorativas y epistémicas suman el $18 \%$, mientras que las expresiones no modalizadas se reducen al 5\%.

${ }^{7}$ El código alfanumérico de los ejemplos indica el tipo de texto y el informante.
} 
a la despersonalización de la instrucción, que se expresa de manera general de modo que el lector no se sienta directamente concernido por ella.

Las subordinadas sustantivas con función de sujeto en forma de pasiva refleja son las menos frecuentes, pues dan cuenta de apenas el 8,49\%. Como hemos visto, esta opción es prototípica de los entornos narrativos; así y todo, esta afirmación ha de valorarse considerando que el género textual evaluado en este trabajo es la noticia periodística. En ella tal elección responde a una estrategia discursiva conducente a la ocultación de voces textuales irrelevantes. La pasiva refleja persigue, como la construcción impersonal, esconder un argumento, que en el caso de las primeras sería el complemento agente ( $N G L E 41.12 \mathrm{a})$, elemento que no aparece sino de forma muy excepcional (NGLE 41.1h). Su empleo se distribuye de este modo:

\begin{tabular}{l|lll} 
PASIVAS REFLEJAS & Indicativo & Subjuntivo & No personal \\
\hline Narrativo & $63,04 \%$ & $21,74 \%$ & $15,22 \%$ \\
Descriptivo & $40,00 \%$ & $0,00 \%$ & $60,00 \%$ \\
Instructivo & $21,95 \%$ & $9,76 \%$ & $68,29 \%$ \\
Expositivo & $50,00 \%$ & $9,38 \%$ & $40,63 \%$ \\
Promedio & $45,16 \%$ & $13,71 \%$ & $41,13 \%$
\end{tabular}

Tabla 9. Función de sujeto: pasivas reflejas

La tendencia a usar el indicativo tres veces más que el subjuntivo se explica si tenemos en cuenta que los verbos que aceptan tales subordinadas en un 60\% de los casos «expresan nociones relativas a la argumentación» (NGLE: 43.4c) o bien indican opiniones atenuadas:

(3) De esta manera se demostró que el intento de homicidio fue instigado por un chantajista que amenazaba con asesinar personalmente a toda la familia de María Borjas, incluida ella misma. (NA-4)

Las subordinadas sustantivas con función de sujeto de naturaleza predicativa son propias del discurso descriptivo, donde se asocian habitualmente a la construcción de retratos de naturaleza expresiva: un 95\% de lo predicados verbales identificados aparece en textos vinculados a la descripción de seres humanos y casi el $80 \%$ de los casos se construye con los 
verbos gustaro encantar. De hecho, en un 73\% de las ocasiones la oración subordinada es sujeto de un verbo de afección.

La variedad morfológica de los verbos subordinados se distribuye ahora de la siguiente manera:

\begin{tabular}{l|lll} 
PREDICATIVAS & Indicativo & Subjuntivo & No personal \\
\hline Narrativo & $0,00 \%$ & $0,00 \%$ & $100,00 \%$ \\
Descriptivo & $5,13 \%$ & $14,10 \%$ & $80,77 \%$ \\
Instructivo & $3,70 \%$ & $20,99 \%$ & $75,31 \%$ \\
Expositivo & $7,59 \%$ & $16,46 \%$ & $75,95 \%$ \\
Promedio & $5,37 \%$ & $16,94 \%$ & $77,69 \%$
\end{tabular}

Tabla 10. Función de sujeto: predicativas

Interesa destacar que casi el $78 \%$ de estas construcciones predicativas lo hacen sobre un infinitivo asociado normalmente a un verbo de afección o desafección. El resto prefiere el subjuntivo antes que el indicativo:

(4) Le gusta vestir con la ropa que se lleva, pero sin perder su estilo. (DE-43)

(5) Sin embargo, me desagrada que se pase de borde y que lo pague con el primero que encuentra si está de mal humor. (DE-19)

El elevado rendimiento de las construcciones de infinitivo se explica desde la naturaleza discursiva del texto donde estas aparecen habitualmente: al tratarse de un contexto descriptivo, es lógica la identidad de sujetos, toda vez que la expresión de gustos y disgustos es una estrategia habitual en la caracterización de la personalidad humana, sin duda más frecuente que la expresión de valoraciones del yo enunciador respecto de la persona descrita, que sería el espacio para el empleo del subjuntivo.

\subsection{En función de complemento directo}

La función de complemento directo es la más habitual de las oraciones subordinadas sustantivas y suma el $41,86 \%$ de los casos consignados. No obstante, el modo del discurso afecta de manera muy directa a la frecuencia de uso correspondiente a esta opción. Así, esta será la propia de casi dos de cada tres subordinadas sustantivas identificadas en contextos 
narrativos. En el extremo opuesto se encuentran los entornos instructivos, donde el rendimiento desciende casi a la mitad.

Si nos fijamos en la naturaleza del verbo de la oración subordinada en términos globales, los datos indican que se tiende casi en la mitad de los casos a optar por el indicativo, mientras que la construcción en subjuntivo se reduce a algo menos de una cuarta parte. En una tercera parte de los casos se construyen oraciones subordinadas de infinitivo:

\begin{tabular}{l|lll}
\multicolumn{1}{l|}{ Tipo } & Indicativo & Subjuntivo & Infinitivo \\
\hline Narrativo & $65,74 \%$ & $12,81 \%$ & $21,45 \%$ \\
Descriptivo & $48,20 \%$ & $12,23 \%$ & $39,57 \%$ \\
Instructivo & $27,62 \%$ & $30,95 \%$ & $41,43 \%$ \\
Expositivo & $49,29 \%$ & $23,46 \%$ & $27,24 \%$ \\
Promedio & $45,33 \%$ & $22,16 \%$ & $32,51 \%$
\end{tabular}

Tabla 11. Función de complemento directo y morfología verbal

A la hora de valorar el empleo del indicativo y el subjuntivo, nos fijaremos en la naturaleza semántica del verbo de la oración principal ${ }^{8}$. Para ello hemos clasificado todos los predicados verbales involucrados a partir de la propuesta realizada por el proyecto ADESSE ${ }^{9}$.

\footnotetext{
${ }^{8}$ Como bien apunta Demonte Barreto (2015: 90): «(e)l análisis de las clases lógicas y léxicas de los predicados que seleccionan subordinadas sustantivas es, pues, central. [...] La distinción entre las clases de verbos del español que seleccionan indicativo y subjuntivo se estudia en Quer (1998) y en Bosque (2012)». Este trabajo dedica todo un epígrafe, ciertamente interesantísimo, a los tipos semánticos de subordinadas sustantivas y los tipos semánticos de predicados.

${ }^{9}$ Este proyecto ha sido dirigido por José M. García Miguel, profesor de la Facultad de Filoloxía e Tradución de la Universidad de Vigo. Véanse, entre otros, García Miguel, Costas y Martínez (2005), y Albertuz Carneiro (2007). Toda la información referida al excelente trabajo llevado a cabo está disponible en <http://adesse.uvigo.es $>$ : «ADESSE es una base de datos de verbos y construcciones verbales del español con el análisis sintáctico-semántico de un corpus, y que permite ofrecer para cada verbo una completa caracterización sintáctico-semántica, con sus alternancias de diátesis junto con las frecuencias relativas de cada alternativa construccional para relaciones semánticas similares. ADESSE es una versión ampliada de la Base de Datos Sintácticos del español actual (BDS) que contiene información sintáctico-semántica sobre las cláusulas y los verbos registrados en un corpus del español (Arthus) de 1,5 millones de palabras». Otras propuestas de clasificación verbal para el estudio de la subordinación sustantiva pueden consultarse en Bermejo Calleja (2012 y 2015).
} 
De las predicaciones verbales identificadas en indicativo, el $80 \%$ responde a cuatro de las categorías propuestas por ADESSE. Se trata, en orden de frecuencia, de los verbos de comunicación $(33,79 \%)$, conocimiento $(21,03 \%)$, creencia $(13,43 \%)$ y cognición $(10,99 \%)$. Por su parte, en el caso de las formas verbales en subjuntivo, hay que sumar seis categorías para reunir un $75 \%$ : causación $(17,60 \%)$, disposición $(16,48 \%)$, petición $(13,41 \%)$, permiso $(9,78 \%)$, volición $(9,22 \%)$ y adquisición $(8,10 \%)$.

Tal reparto no es en absoluto uniforme, pues la naturaleza discursiva de los textos afecta, y mucho, a la distribución de las alternativas formales. De hecho, se observan diferencias importantes entre el contexto narrativo y descriptivo, por un lado, y el instructivo y el expositivo, por otro.

En el discurso narrativo la construcción en indicativo alcanza casi las dos terceras partes de las formas identificadas. Esta inclinación tiene que ver con el género evaluado, que es la noticia periodística. Tal hecho se hace evidente si nos fijamos en la naturaleza de los verbos de los que dependen dichas construcciones. La elevada frecuencia del indicativo se asocia al uso en la oración principal de verbos de comunicación $(60,64 \%)$ y, secundariamente, de percepción $(10,11 \%)$. Por su parte, el subjuntivo se utiliza en construcciones formalizadas a partir de verbos cuyo contenido es mucho más diverso. El grupo más usado es el de petición $(25,58 \%)$; después, existencia y causación, ambos con un $13,95 \%$ :

(6) El doctor le dijo que probablemente sufría de indigestión y que no debía preocuparse. (NA-28)

En los contextos descriptivos, el indicativo es también la opción más frecuente, aun cuando su uso se reduce en beneficio de las construcciones de infinitivo, que doblan su presencia. En cuanto a la naturaleza de los verbos de los que depende el indicativo, predominan los de conocimiento $(25,64 \%)$ y comunicación $(29,91 \%)$. El uso del subjuntivo sigue siendo muy limitado y con una proporción similar a la consignada en los entornos narrativos, aunque se concentra aún más en el contexto de los verbos de influencia; los más frecuentes son causación $(37,04 \%)$ y volición $(18,52 \%)$ :

(7) Tiene una personalidad optimista y alegre, siempre que puede se ríe, e intenta animar a quien ella sabe que está deprimido. (DE-4) 
En el texto instructivo se han identificado más subordinadas sustantivas de complemento directo en subjuntivo que en indicativo. Asimismo, es el único contexto en el que la construcción asentada en una forma no personal resulta ser la opción más habitual. El subjuntivo se construye habitualmente a partir de verbos con mucha carga deóntica. Tal hecho tiene como resultado que los más empleados sean los de disposición $(24,24 \%)$ y los de petición $(20 \%)$. En las construcciones con indicativo hay además un cambio cualitativo fundamental, pues la construcción sobre la base de verbos de conocimiento reúne nada menos que un 45,51\% de los casos. Además, exhiben un matiz deóntico muy marcado, que se observa de manera más que evidente en el caso del verbo más usado, que es recordar.

(8) Recuerde que la clásica es la más adecuada, y debe ponerla siempre a bajo volumen. (IN-33)

En los textos expositivos el uso del indicativo es cuantitativamente similar al observado en los descriptivos y los verbos de comunicación siguen siendo los más usados, con una proporción del 26,45\%. Sin embargo, hay algunas diferencias cualitativas importantes, pues los siguientes grupos más empleados son ahora los de creencia $(23,55 \%)$ y cognición $(18,12 \%)$. El porcentaje de subjuntivo duplica el consignado en los entornos narrativos y descriptivos, y el nivel de dispersión es mayor. En cualquier caso, los más empleados son los de causación $(21,95 \%)$ :

(9) Todo hace que la obesidad sea casi inevitable y si no se corrigen estos hábitos puede llegar a ser permanente. (EX-3)

\subsection{En función de complemento de régimen preposicional}

\subsubsection{Complemento del verbo (CRV)}

Esta es la tercera función más frecuente en nuestro corpus y reúne en torno al 13\% de los casos. Observamos, además, que el uso es muy estable en los cuatro modos del discurso analizados, como lo demuestra el hecho de que oscila entre el $12 \%$ y el $15 \%$. 
El verbo en la subordinada sustantiva exhibe ahora una tendencia muy evidente a construirse en infinitivo. No obstante, hay ciertas diferencias en la configuración morfológica según la naturaleza tipológica de los textos:

\begin{tabular}{l|lll}
\multicolumn{2}{c}{ Indicativo } & Subjuntivo & No Personal \\
\hline Narrativo & $22,97 \%$ & $10,81 \%$ & $66,22 \%$ \\
Descriptivo & $28,57 \%$ & $10,20 \%$ & $61,22 \%$ \\
Instructivo & $19,13 \%$ & $18,03 \%$ & $62,84 \%$ \\
Expositivo & $8,60 \%$ & $12,22 \%$ & $79,19 \%$ \\
Promedio & $16,13 \%$ & $13,85 \%$ & $70,02 \%$
\end{tabular}

Tabla 12. Función de CRV y morfología verbal

Importa destacar que el verbo más empleado tanto seguido de indicativo $(24,7 \%)$ como de subjuntivo $(30,56 \%)$ es asegurarse de. Por su parte, en la construcción con infinitivo, los dos más utilizados son ayudar a $(196,94 \%)$ y obligar a $(10,38 \%)^{10}$ :

(10) A la hora de dejar a su hijo al cuidado de un extraño, asegúrese de que sea una persona de confianza. (IN-25)

\subsubsection{Complemento del nombre (CRN)}

El rendimiento medio de las subordinadas sustantivas en función de complemento de régimen del nombre se sitúa en nuestro corpus en el11\%. Hemos identificado 110 sustantivos diferentes a partir de los cuales se construyen estas subordinadas; no obstante, el 56\% de los casos depende de apenas nueve. Son, en orden de presencia, los siguientes: hora $(18,26 \%)$, forma $(10,17 \%)$, hecho $(7,26 \%)$, manera $(5,39 \%)$, posibilidad $(4,15 \%)$, momento $(3,73 \%)$, necesidad $(2,90 \%)$, riesgo $(2,90 \%) \mathrm{y}$ caso $(2,07 \%)$ :

(11) Cuando empieces a sentir las primeras contracciones, quiere decir que es la hora de ir al hospital. (IN-3)

${ }^{10}$ Se han consignado 26 verbos diferentes con indicativo, 27 con subjuntivo y 87 con infinitivo. 
En cuanto a la preposición que enlaza la subordinada observamos que el rendimiento de las distintas opciones permanece muy estable en todos los modos del discurso. La forma de su utiliza en la inmensa mayoría de las ocasiones:

\begin{tabular}{l|lllll}
\multicolumn{2}{c}{ Promedio } & Narrativo & Descriptivo & Instructivo & Expositivo \\
\hline A & $5,05 \%$ & $6,06 \%$ & $5,26 \%$ & $4,73 \%$ & $5,07 \%$ \\
Con & $0,44 \%$ & & & $0,68 \%$ & $0,46 \%$ \\
De & $90,99 \%$ & $87,88 \%$ & $84,21 \%$ & $91,89 \%$ & $92,63 \%$ \\
En & $2,42 \%$ & & & $2,03 \%$ & $1,38 \%$ \\
Por & $1,10 \%$ & $6,06 \%$ & $1,75 \%$ & $0,68 \%$ & $0,46 \%$
\end{tabular}

Tabla 13. Función de CRN: preposiciones usadas

Estas construcciones optan por una forma verbal en infinitivo en el $78 \%$ de las ocasiones:

\begin{tabular}{l|lll}
\multicolumn{2}{c}{ Indicativo } & Subjuntivo & Infinitivo \\
\hline Narrativo & $27,03 \%$ & $18,92 \%$ & $54,05 \%$ \\
Descriptivo & $3,95 \%$ & $14,47 \%$ & $81,58 \%$ \\
Instructivo & $3,29 \%$ & $3,29 \%$ & $93,42 \%$ \\
Expositivo & $8,94 \%$ & $11,49 \%$ & $79,57 \%$ \\
Promedio & $12,57 \%$ & $9,28 \%$ & $78,14 \%$
\end{tabular}

Tabla 14. Función de CRN y morfología verbal

\subsubsection{Complemento del adjetivo (CRA)}

Asumimos como cierta la afirmación de la NGLE, según la cual «(s)on numerosos los adjetivos que admiten complementos de régimen formados con subordinadas sustantivas declarativas» (NGLE, 43.5p). Así y todo, el uso de esta opción es ciertamente muy limitado en nuestro corpus: apenas supera el $1 \%$ en los contextos descriptivo y expositivo.

Solo las preposiciones ay de exhiben un rendimiento superior al $20 \%$, lo que nos permite hacer alguna valoración referida a cómo se emplean 
una y otra. De hecho, entre ambas acumulan algo más del $96 \%$ los casos consignados:

\begin{tabular}{|c|c|c|c|c|}
\hline Preposiciones & Promedio & Indicativo & Subjuntivo & Infinitivo \\
\hline$A$ & $20,65 \%$ & $5,26 \%$ & $0,00 \%$ & $94,74 \%$ \\
\hline Con & $1,09 \%$ & $100,00 \%$ & & \\
\hline De & $76,09 \%$ & $16,22 \%$ & $2,70 \%$ & $81,08 \%$ \\
\hline En & $2,17 \%$ & & $50,00 \%$ & $50,00 \%$ \\
\hline Total & $100,00 \%$ & $14,58 \%$ & $3,13 \%$ & $82,29 \%$ \\
\hline
\end{tabular}

Tabla 15. Función de CRA: preposiciones usadas

La primera de ellas aparece en cerca de un $22 \%$ de los ejemplos y se construye casi exclusivamente con infinitivo. 12 de los 19 ejemplos identificados se apoyan en los adjetivos propenso y dispuesto y el uso de limita a contextos descriptivos (42\%) y expositivos (47\%):

(12) Lys siempre se ha preocupado por los demás y se ha mostrado dispuesta a ayudarlos. (DE-36)

Por su parte, de encabeza tres de cada cuatro subordinadas sustantivas de complemento preposicional del adjetivo y exhibe unas mayores posibilidades combinatorias. Así, el uso del indicativo roza el 18\% y el infinitivo acumula casi el 80\%. El 66\% de los casos en los que se usa la preposición de se construye sobre cuatro adjetivos: capaz $(33,8 \%)$, difícil $(15,49 \%)$, fácil $(8,45 \%)$ y seguro $(8,45 \%)$ :

(13) Son trastornos difíciles de tratar y, además, afectan psicológicamente tanto a los niños que la sufren como a los padres de los mismos. $(E X-6)$

\section{CONSTRUCCIONES INDIRECTAS Y DE ESTILO DIRECTO}

En lo que se refiere a las construcciones indirectas, interesa destacar que el $88 \%$ de los predicados consignados corresponde a interrogativas, 
mientras que solo el 12\% aparece en exclamativas. En el corpus se recogen ejemplos referidos a nueve adverbios y un uso enfático del artículo determinado (lo...que $)^{11}$. Esta es la distribución de uso:

\begin{tabular}{l|lllll}
\multicolumn{1}{l|}{} & Narrativo & Descriptivo & Instructivo & Expositivo & Promedio \\
\hline Cómo & $38,46 \%$ & $27,50 \%$ & $40,85 \%$ & $28,44 \%$ & $32,93 \%$ \\
Qué & $15,38 \%$ & $25,00 \%$ & $26,76 \%$ & $27,52 \%$ & $25,61 \%$ \\
Si & $19,23 \%$ & $12,50 \%$ & $11,27 \%$ & $23,85 \%$ & $17,89 \%$ \\
Lo...que & $3,85 \%$ & $17,50 \%$ & $1,41 \%$ & $5,50 \%$ & $6,10 \%$ \\
Cuál & $7,69 \%$ & $5,00 \%$ & $7,04 \%$ & $1,83 \%$ & $4,47 \%$ \\
Quién & $0,00 \%$ & $2,50 \%$ & $5,63 \%$ & $5,50 \%$ & $4,47 \%$ \\
Por qué & $0,00 \%$ & $2,50 \%$ & $2,82 \%$ & $6,42 \%$ & $4,07 \%$ \\
Cuándo & $3,85 \%$ & $2,50 \%$ & $4,23 \%$ & $0,00 \%$ & $2,03 \%$ \\
Cuánto & $7,69 \%$ & $2,50 \%$ & $0,00 \%$ & $0,00 \%$ & $1,22 \%$ \\
Dónde & $3,85 \%$ & $2,50 \%$ & $0,00 \%$ & $0,92 \%$ & $1,22 \%$
\end{tabular}

Tabla 16. Nexos usados en las construcciones indirectas

Cómo es el nexo preferido en las construcciones indirectas. Junto a él, solo qué y si tienen un promedio de aparición por encima del 10\%. De hecho, entre los tres suman más del $75 \%$ de los casos consignados. El dato importa si consideramos que el $25 \%$ restante se distribuye entre siete alternativas distintas:

(14) Cuentan, también, que sobre las 3 de la mañana, hora local, se escuchó cómo el viento arrancaba los tejados de los pabellones y se escucharon explosiones en los cables de alta tensión. (NA-29)

(15) Me cuesta realmente decidir qué es lo que más me gusta de ella, porque no son pocas las cosas. (DE-24)

(16) Con la llegada del Partido Popular al gobierno, se volvío a abrir el debate sobre si en los centros públicos debería ser obligatorio el uniforme. (EX-5)

Cómo precede al $48 \%$ de las exclamativas indirectas. La otra mitad utiliza construcciones enfáticas de articulo determinado. La NGLE (42.16b) reconoce que estas se pueden presentar en tres contextos: oraciones subordinadas a un predicado que selecciona exclamativas indirectas, oraciones exclamativas independientes y oraciones subordinadas a predicados que seleccionan interrogativas indirectas. No obstante, en

${ }^{11}$ Este uso aparece definido en la $N G L E(\S 42.16)$. 
nuestro corpus solo aparecen en exclamativas indirectas. Tampoco hemos registrado ningún caso en las 40 exclamativas independientes. Con todo, hemos de indicar que solo se han incluido dentro de este grupo aquellos casos en los que el artículo determinado es lo, pues resulta difícil distinguir las restantes de las oraciones de relativo, especialmente cuando se trata de construcciones indirectas. Tal dificultad aparece reconocida en el epígrafe 42.16e del texto académico.

El uso de las construcciones indirectas varía según el tipo de texto: sin duda, el mayor rendimiento lo alcanzan en el texto instructivo y, muy especialmente, en el expositivo. Las predicaciones de esta naturaleza que hemos consignado se reparten del modo siguiente:

Narrativo Descriptivo Instructivo Expositivo

\begin{tabular}{l|llll} 
Construcciones indirectas & $9,96 \%$ & $16,33 \%$ & $29,48 \%$ & $44,22 \%$
\end{tabular}

Tabla 17. Construcciones indirectas y modo del discurso

Hay, además, algunos rasgos interesantes. En primer lugar, vemos que la secuencia de adverbios más frecuentes varía según la naturaleza de los textos. Así, en los narrativos, el uso de si supera al de qué. Por su parte, en los descriptivos el uso enfático del artículo determinado adelanta en frecuencia a si asociado a una modalidad exclamativa y se convierte en una construcción distintiva de tales secuencias. Finalmente, llama la atención que solo en las secuencias expositivas los tres nexos más usados presentan un rendimiento muy parejo, superior en todos los casos al 20\%. Tal hecho contrasta con las instrucciones y las narraciones, donde la frecuencia de uso de cómo asciende hasta el $40 \%$, en perjuicio de siy qué respectivamente.

Las construcciones de estilo directo no aparecen recogidas como tales de manera explícita en la $N G L E$ dentro de las clases de subordinadas sustantivas, aun cuando sí las incluye en el capítulo 43, dedicado al estudio del estilo directo y el estilo indirecto (epígrafes 43.9 y siguientes). Para su consideración asumimos la posición defendida entre otros por Gutiérrez Ordóñez (1997) Sostiene que, aunque no aparece de modo explícito un transpositor, estas responden a las pruebas de sustantivación oracional. En su opinión, la nominalización es fruto de la inclusión de 
una pausa ortográfica. Prueba de lo atinado de su observación es que todas las subordinadas sustantivas de estilo directo consignadas en nuestro corpus marcan los límites oracionales mediante signos de puntuación, si bien no son siempre los mismos. Los datos son los siguientes:

\begin{tabular}{|c|c|c|c|c|c|}
\hline & $\begin{array}{l}\text { Narra- } \\
\text { tivo }\end{array}$ & $\begin{array}{l}\text { Descrip- } \\
\text { tivo }\end{array}$ & $\begin{array}{l}\text { Instruc- } \\
\text { tivo }\end{array}$ & $\begin{array}{l}\text { Exposi- } \\
\text { tivo }\end{array}$ & $\begin{array}{l}\text { Prome- } \\
\text { dio }\end{array}$ \\
\hline Comillas + Coma & $56,45 \%$ & & & & $50,00 \%$ \\
\hline Comillas & $16,13 \%$ & & $100,00 \%$ & $40,00 \%$ & $20,00 \%$ \\
\hline Coma & $9,68 \%$ & & & $40,00 \%$ & $11,43 \%$ \\
\hline Comillas + Dos puntos & $4,84 \%$ & $100,00 \%$ & & $20,00 \%$ & $7,14 \%$ \\
\hline Comillas + Guion & $4,84 \%$ & & & & $4,29 \%$ \\
\hline Coma + Como & $3,23 \%$ & & & & $2,86 \%$ \\
\hline Coma + Según & $3,23 \%$ & & & & $2,86 \%$ \\
\hline Dos puntos & $1,61 \%$ & & & & $1,43 \%$ \\
\hline
\end{tabular}

Tabla 18. Puntuación en las construcciones de estilo directo

Parece que nuestros informantes asocian ante todo el estilo directo a las comillas, presentes en un $81 \%$ de los ejemplos. Por su parte, la coma aparece en un $67 \%$ de ellos. De hecho, la inserción del estilo directo se hace normalmente mediante la combinación de estos dos signos ortográficos o bien mediante el uso de solo uno:

(17) "No puede haber indulto por lo que ha hecho", sentenció un familiar de la víctima. (NA-3)

En cambio, los ejemplos en los que los dos puntos se emplean en lugar de las comillas resultan muchísimo menos habituales:

(18) Vallés ha declarado: pensaba que ya se había olvidado. (NA-23)

Muy llamativa, aunque a todas luces innecesaria, resulta la combinación en narraciones de las comillas y los guiones, pues estos son esperables en los géneros asociados al relato de ficción y para fijar la intervención de voces textuales distintas:

(19) "Por lo tanto, creo que deben pagar por ello."-declaraba la madre del joven entre lágrimas esta misma tarde, sin saber aun el resultado final del juicio. (NA-26)

Por último, cabe destacar cuatro casos en los que la puntación se refuerza con un adverbio de modo, que puede ser como o según: 
(20) La evacuación de más de un millón de personas se complicó porque muchas zonas ya estaban incomunicadas cuando se intentó acceder a ellas, como explica el portavoz del cuerpo militar encargado de los rescates. (NA-2)

El 88\% de las construcciones de estilo directo identificadas en nuestro trabajo aparece en contextos narrativos, lo que no nos sorprende, pues los textos que redactaron nuestros informantes emulaban un género, la noticia periodística, en el que el discurso referido cumple una función perfectamente definida en la construcción de la verosimilitud de la información. El escaso rendimiento en las secuencias expositivas $(7,5 \%)$ tiene que ver con que el género representado, el texto de opinión, y con la extensión del mismo, 400 palabras aproximadamente, que reduce el uso de referencias intertextuales en apoyo de las tesis defendidas. Por su parte, en contextos descriptivos e instructivos su rendimiento es mínimo.

\section{CONCLUSIÓN}

La investigación realizada se asienta en el hecho de que, de manera global, la subordinación sustantiva es la más empleada en el texto escrito en español y alcanza un promedio del $37,83 \%$. No obstante, nuestro estudio nos confirma que tal hecho ha de matizarse cuando se consideran los diferentes modos del discurso. Dicho de otro modo, su rendimiento en la expresión escrita está claramente supeditada a la naturaleza tipológica de los textos. Y ese condicionamiento se verifica en varios niveles, como son la función de la subordinada, la variedad morfológica de los predicados verbales y la categoría enunciativa de las unidades.

El discurso narrativo emplea la subordinación sustantiva algo por debajo de la media $(34,58 \%)$ y le asigna en dos de cada tres ocasiones una función de complemento directo $(64,45 \%)$. Con esta función se prefiere de manera evidente una construcción en indicativo (66\%), asentada normalmente en verbos de comunicación, percepción y conocimiento En segundo lugar, observamos que es el contexto en el que menos se recurre a emplear las sustantivas con función de sujeto: apenas una de cada seis. Cuando lo hace, se opta normalmente por construcciones de pasiva refleja que serán distintivas de este modo del discurso y que se construyen 
en la mayor parte de las ocasiones (66\%) seguidas de indicativo. Por último, las construcciones de estilo directo encuentran en este modo del discurso su espacio natural: casi el $90 \%$ de las consignadas en nuestro estudio aparecen en contextos narrativos.

El texto descriptivo es el único en el que la subordinación sustantiva no es la más empleada, y desciende hasta el $22,55 \%$, frente a las oraciones de relativo, que alcanzan el $33,11 \%$. Así y todo, cuando se emplea la sustantiva, cumple casi en la mitad de los casos una función de complemento directo $(45,25 \%)$; en este caso, se prefiere la construcción con indicativo $(48,20 \%)$, preferentemente con verbos de conocimiento, comunicación y percepción física; no obstante, se debe subrayar que las construcciones de infinitivo tienen un rendimiento muy elevado $(38,57 \%)$. En segundo término, hemos confirmado que un tercio de las sustantivas en la descripción tienen función de sujeto y se opta normalmente por variantes atributivas $(57 \%)$ o predicativas $(40 \%)$ : estas últimas son distintivas de la descripción y se construyen en casi el $80 \%$ de las ocasiones sobre un infinitivo dependiente de un verbo de afección o desafección.

El texto expositivo utiliza la subordinación sustantiva por encima del promedio de empleo global $(43,69 \%)$ y es el único contexto discursivo en el que el uso se distribuye de manera muy uniforme, pues las de complemento directo suman el 38\%; las de sujeto, el 30\%; y las de complemento de régimen, el $32 \%$. En el caso de las subordinadas de complemento directo, destaca que el empleo del subjuntivo $(23,46 \%)$ duplica al consignado en entornos narrativos y descriptivos, aunque sigue siendo muy inferior al del indicativo $(49,29 \%)$. Este se combina con verbos de creencia, cognición y conocimiento; por su parte, el subjuntivo se asocia a verbos de causación, disposición, permiso, adquisición o creencia. En segundo lugar, en lo que atañe a las sustantivas con función de sujeto, se opta casi siempre por las construcciones atributivas (77\%), normalmente construidas con un infinitivo. En tercer lugar, debemos destacar que es en el discurso expositivo cuando las funciones de complementos de régimen son las más elevadas para las tres opciones estudiadas, y siempre por encima de las medias totales. Dentro de ellas, interesa subrayar el rendimiento de las de CRN: tienden a construir complementos que dependen de sustantivos de significado abstracto, configurando complementos de los lla- 
mados apositivos. Finalmente, importa subrayar que los textos expositivos son el contexto más adecuado para las construcciones indirectas, pues en ellos se consigna el $44 \%$ de los casos identificados.

El discurso instructivo es el que más emplea la subordinación sustantiva $(44,93 \%)$. Sin embargo, lo hace de manera muy diferente; de hecho, es el único contexto en el que las subordinadas de sujeto $(40,74 \%)$ son las más empleadas. En ellas, la construcción más repetida es la atributiva, fundamentalmente para construir expresiones de una elevada modalización deóntica. En segundo lugar, por lo que afecta a las de complemento directo, hemos confirmado dos hechos distintivos: por un lado, que las más frecuentes son las de infinitivo (41,43\%); por otro, que se construyen antes con subjuntivo $(30,95 \%)$ que con indicativo $(27,62 \%)$. El indicativo se combina con verbos de conocimiento y de comunicación, mientras que el subjuntivo se asocia a los de disposición, petición y volición. Por último, importa señalar que las construcciones indirectas son también propias de la instrucción, que alberga un 30\% de los ejemplos consignados.

\section{BIBLIOGRAFÍA CITADA}

ALBERTUZ CARNEIRO, F. (2007): «Sintaxis, semántica y clases de verbos: clasificación verbal en el proyecto ADESSE». En Cano López, P. (ed.): Actas del VI Congreso de Lingüística General. Vol IIb Las lenguas y su estructura. Madrid, Arco Libros, págs. 2015-2030.

Bermejo Calleja, F. (2012): «Verbo y oración sustantiva. Propuesta de clasificación contrastiva». En Lombardini, H. y Pérez Vázquez, M.E. (eds.): Núcleos. Estudios sobre el verbo en español e italiano. Berna, Peter Lang, págs. 145-162.

- (2015): «La subordinación sustantiva». En San Vicente, F. (ed.): Gramática de referencia para italófonos. Bologna-Salamanca, ClueB-Universidad de Salamanca, págs. 1091-1132.

Bustos GISBERT, J.M. (2017): «Naturaleza sintáctica de los enunciados textuales en el discurso escrito». ELUA, 31, págs. 67-95.

- (2018): «Bases para el estudio de las características sintácticas del discurso escrito». Dicenda, 36, págs. 89-114. 
DEMONTE BARRETO, V. (2015): «Subordinación sustantiva». En Gutiérrez Rexach, J. (ed.): Enciclopedia de Lingüística Hispánica. Londres, Routledge, págs. 88-100.

Di Tullio, A. (2002): «Gramática y texto escrito. Las trampas de la coordinación». Propuestas de Rosario, 7, págs. 57-66.

García Miguel, J.M.; Costas, L. y MartíneZ, S. (2005): «Diátesis verbales y esquemas construccionales. Verbos, clases semánticas y esquemas sintácticosemánticos en el proyecto ADESSE». En Wotjak, G. y Cuartero Otal, J. (eds.): Entre semántica léxica, teoría del léxico y sintaxis. Frankfurt am Main, Peter Lang, págs. 373-384.

GUTIÉRREZ ORDÓÑEZ, S. (1997): «Comentario sintáctico». En: La oración y sus funciones. Madrid, Arco Libros, págs. 577-598.

LEONETTI JUNGL, M. (1999): «La subordinación sustantiva: las subordinadas enunciativas en los complementos nominales». En Bosque Muñoz I. y Demonte Barreto V. (eds.): Gramática descriptiva de la lengua española II. Madrid, Espasa, págs. 2083-2104.

RAE (2009): Nueva Gramática de la Lengua Española. Madrid, Espasa.

José M. Bustos GisBerT Universidad de Salamanca jbustos@usal.es 0000-0001-9239-610X 